\title{
Aproveitamento da casca de banana na elaboração de doce tipo mariola
}

\section{Use of banana peel in the elaboration of candy mariola type}

\author{
Juvêncio Olegário de OLIVEIRA NETO'; Emanuel Neto Alves de OLIVEIRA²; \\ Bruno Fonsêca FEITOSA ${ }^{1}$; Antônia Maria Luiza de Oliveira GERMANO ${ }^{3}$; Regilane Marques FEITOSA ${ }^{4}$ \\ ${ }^{1}$ Graduando em Engenharia de Alimentos, Universidade Federal de Campina Grande. E-mail: \\ juvencio_oliveira12@hotmail.com; brunofonsecafeitosa@live.com \\ ${ }^{2}$ Autor para correspondência: Doutor em Engenharia Agrícola, Instituto Federal de Educação, Ciência e Tecnologia dos Rio \\ Grande do Norte, campus Pau dos Ferros, BR 405, km 154, S/N, Bairro Chico Cajá, Pau dos Ferros-RN, Brasil. E-mail: \\ emanuel.oliveira16@gmail.com \\ ${ }^{3}$ Técnica em Alimentos. E-mail: maria-luiza-8@hotmail.com \\ ${ }^{4}$ Pós-doutoranda em Engenharia Agrícola, Universidade Federal de Campina Grande. E-mail: regilanemarques@gmail.com
}

\section{Recebido em: 13-07-2017; Aceito em: 01-02-2018}

\section{Resumo}

O Brasil é um dos maiores produtores de banana. Os excedentes de safras e as limitações da vida útil dessa fruta provocam elevados índices de desperdício, gerando um problema ambiental, principalmente no que se refere às cascas descartadas durante o processamento. Portanto, objetivou-se com este trabalho elaborar e caracterizar as propriedades físico-químicas e sensoriais de um doce tipo mariola de banana com o aproveitamento total da fruta pela adição da farinha da casca. Para isso, desenvolveram-se três formulações de doces, adicionados da farinha da casca de banana: $F_{1}(0 \%), F_{2}(5 \%)$ e $F_{3}(10 \%)$, submetidas às análises físico-químicas de umidade, açúcares, acidez, sólidos solúveis, atividade de água, pH e Ratio. Ainda verificou-se a aceitação sensorial para cor, aroma, aparência, sabor, consistência, doçura, aceitação global, bem como a intenção de compra. Os doces atenderam ao parâmetro legislativo de sólidos solúveis totais, porém a substituição da polpa pela farinha interferiu, reduzindo os parâmetros de açúcares totais, Ratio e atividade de água. Os produtos apresentaram boa aceitação sensorial, com índice de aceitação para $F_{1}, F_{2}$ e $F_{3}$ de, respectivamente, 85,05\%, $74,98 \%$ e 70,60\%, mostrando que, a diminuição nas concentrações de farinha aumentou a aceitação. Os doces possuem boas perspectivas, sendo uma alternativa viável para o reaproveitamento dos resíduos da banana. Porém, os resíduos devem ser elaborados em concentrações inferiores a 10\%, visando à melhor aceitação do produto.

Palavras-chave adicionais: Doce em massa; Musa spp.; Resíduos agroindustriais.

\begin{abstract}
Brazil is the largest producer of banana in the world. The surplus harvests and limitations in the useful life of this fruit provoke high rates of waste, generating an environmental problem, mainly as far as the barks discarded during the processing are concerned. Therefore, the objective of this work was to elaborate and characterize the physical-chemical and sensory properties of a candy mariola type of banana with the total use of the fruit by the addition of the flour of the bark. For this, three formulations of sweetmeats were prepared, with the addition of the banana peel flour: F1 (0\%), F2 (5\%) and F3 (10\%), submitted to physicochemical analyzes of moisture, sugars, acidity, soluble solids, water activity, $\mathrm{pH}$ and Ratio. There was still sensory acceptance for color, aroma, appearance, taste, consistency, sweetness, overall acceptance as well as the intention to purchase. However, the substitution of the pulp by the flour interfered with the reduction of the parameters of total sugars, Ratio and water activity. The products presented good sensory acceptance, with acceptance index for F1, F2 and F3 of respectively $85.05 \%, 74.98 \%$ and $70.60 \%$, showing that the decrease in flour concentrations increased the acceptance. The sweets have good prospects, being a viable alternative for reutilization of the residues of the banana. However, they must be prepared in concentrations below 10\%, aiming at a better acceptance of the product.
\end{abstract}

Additional keywords: Mass candy; Musa spp.; Agroindustrial waste.

\section{Introdução}

A banana (Musa spp.) é o pseudofruto derivado da bananeira, comum nas regiões tropicais e que pode servir como matéria-prima dos doces tipo corte. Ela apresenta uma polpa doce e macia, com elevado valor energético. Devido aos elevados teores de vitaminas e de sais minerais, caracteriza-se como um alimento saudável e de ampla comercialização no território nacional (Li et al., 2010; Rufino et al., 2010).

A indústria alimentícia de processamento da banana contribui para o índice de desperdício, utili- 
zando somente a polpa da fruta. No Brasil, estima-se uma geração de milhões de toneladas de resíduos da casca de banana, o que acarreta prejuízos para a própria indústria, decorrentes dos valores econômico, nutritivo e ambiental, sem o aproveitamento conveniente, segundo Silva et al. (2014).

Os nutrientes presentes na casca, muitas vezes, superam a respectiva polpa, a exemplo das fibras, dos minerais, das vitaminas e dos compostos antioxidantes e bioativos. Por isso, tem crescido o interesse da indústria em utilizar métodos viáveis para o reaproveitamento destes materiais (Storck et al., 2013). A forma de farinha está dentre as principais alternativas baseadas na desidratação com posterior trituração, visando à melhor apresentação e à agregação de valor. Segundo Ebrahimi et al. (2012), esse método (desidratação) consiste na eliminação da água por evaporação, o que concentra os nutrientes, melhora o valor nutricional e auxilia no controle do crescimento microbiano.

O doce tipo massa é definido pela legislação como o produto resultante do processamento adequado das partes comestíveis do fruto, até resultar em uma pasta homogênea que permita o corte. No caso do doce tipo mariola, o doce em massa é cortado em pequenos retângulos, envoltos ou não por açúcar. É obtido pela mistura da polpa amassada da fruta com açúcar e com teor de sólidos solúveis totais superior a 65 Brix (Brasil, 1978).
Objetivou-se com o presente trabalho elaborar e avaliar as propriedades físico-químicas e a aceitação sensorial de doces em massa tipo mariola de banana, adicionados de farinha da casca.

\section{Material e métodos}

\section{Obtenção da farinha e elaboração dos doces}

Para a elaboração do doce e da farinha, foram utilizadas bananas-pacovan (Musa paradisíaca) maduras, obtidas na feira-livre do município de Luís GomesRN. Todos os outros ingredientes utilizados para a produção dos doces foram provenientes do comércio local de Pau dos Ferros-RN.

Para a obtenção das farinhas, as bananas foram despencadas, lavadas em água corrente e seguiram para a higienização. Foram lavadas, sanitizadas em água clorada (10 ppm / 15 min) e enxaguadas para o descascamento. Aplicou-se um tratamento térmico (branqueamento) nas cascas, através da imersão em água a $70^{\circ} \mathrm{C}$ por 10 minutos, seguido de resfriamento por 5 minutos em água a $20^{\circ} \mathrm{C}$.

As cascas foram acomodadas em telas e submetidas à secagem em estufa por 24 horas, a $60{ }^{\circ} \mathrm{C}$, para posterior trituração em liquidificador industrial e peneiramento na forma de farinha fina. Testes preliminares de bancada foram realizados, implicando três formulações nas proporções $F_{1}(0 \%), F_{2}(5 \%)$ e $\mathrm{F}_{3}(10 \%)$ de farinha da casca de banana (Tabela 1$)$.

Tabela 1 - Formulação dos doces tipo mariola. Formulation of mariola type candy.

\begin{tabular}{lccc}
\hline \multirow{2}{*}{ Ingredientes (\%) } & \multicolumn{3}{c}{ Formulações } \\
\cline { 2 - 4 } & $\mathrm{F}_{1}(0 \%)$ & $\mathrm{F}_{2}(5 \%)$ & $\mathrm{F}_{3}(10 \%)$ \\
\hline Polpa de banana & 50,0 & 45,0 & 40,0 \\
Açúcar & 48,5 & 48,5 & 48,5 \\
Farinha da casca de banana & 0,0 & 5,0 & 10,0 \\
Pectina de alto teor de Metoxilação & 1,5 & 1,5 & 1,5 \\
\hline
\end{tabular}

Para a produção dos doces, as polpas de banana foram trituradas até formar uma espécie de purê homogêneo, com auxílio de liquidificador industrial. Já os ingredientes secos foram homogeneizados e posteriormente misturados com a polpa de banana, submetendo a um aquecimento sob agitação manual, até à concentração dos sólidos solúveis totais superiores ou iguais a $73^{\circ}$ Brix. Os doces foram resfriados em bandejas de polietileno para o corte em pequenos tabletes, polvilhados com açúcar e acondicionados em embalagens de polipropileno, vedadas e armazenados em sala climatizada a $20^{\circ} \mathrm{C}$, para posteriores análises sensoriais e físico-químicas.

\section{Avaliações físico-químicas}

Avaliaram-se em triplicata os doces e a farinha de casca de banana quanto aos parâmetros físico-químicos: umidade, acidez titulável total - ATT, pH (IAL, 2008) e atividade de água, através de analisador portátil Novasina, modelo Labstart, a $25^{\circ} \mathrm{C}$. Ainda foram analisados os parâmetros sólidos solúveis totais - SST, Ratio (SST/ATT), açúcares totais, açúcares redutores e açúcares não redutores, para os doces, segundo normas e métodos estabelecidos pelo IAL (2008).

\section{Análise sensorial}

Os produtos desenvolvidos foram submetidos a teste de aceitação sensorial e intenção de compra, com 50 provadores não treinados, conforme as instruções de Dutcosky (2013). As amostras foram servidas em copos plásticos de cor branca com capacidade de $50 \mathrm{~mL}$, codificados com três dígitos aleatórios, foram utilizados $10 \mathrm{~g}$ de cada amostra durante o teste para cada provador.

No teste de aceitação, foram avaliados os atributos aparência, cor, aroma, consistência, sabor, doçura e impressão global, através de escala hedônica de nove pontos: "(9) gostei muitíssimo"; "(8) gostei muito"; "(7) gostei moderadamente"; "(6) gostei ligeiramente"; "(5) gostei/desgostei”; "(4) desgostei ligeiramente"; "(3) desgostei moderadamente"; "(2) desgostei 
muito" e "(1) desgostei muitíssimo". A intenção de compra foi avaliada com uma escala hedônica de cinco pontos: "(5) certamente compraria o produto"; "(4) possivelmente compraria o produto"; "(3) talvez comprasse, talvez não comprasse"; "(2) possivelmente não compraria o produto" e "(1) certamente não compraria o produto".

Com os dados obtidos dos atributos sensoriais, foi calculado o índice de aceitabilidade para cada atributo sensorial, de acordo com a Equação (1).

Índice de aceitabilidade $(\%)=\frac{M}{N} \times 100$

Em que: $M$ é a média do somatório das notas dos julgadores, e $\mathrm{N}$ é o número de pontos utilizados na escala de avaliação.

\section{Análise estatística}

Os dados obtidos nas análises físico-químicas, aceitação sensorial e intenção de compra foram analisados através de Delineamento Inteiramente Casualizado (DIC), com o auxílio do "software" Assistat versão 7.7 beta. Aplicou-se a Análise de Variância (ANOVA), comparando-se as médias pelo teste de Tukey, a $5 \%$ de probabilidade $(p<0,05)$.

\section{Resultados e discussão}

\section{Avaliação físico-química da farinha}

Os resultados físico-químicos referentes à avaliação da farinha de casca de banana estão apresentados na Tabela 2.

Tabela 2 - Caracterização físico-química da farinha da casca de banana. Physicochemical characterization of banana peel flour.

\begin{tabular}{lc}
\hline Parâmetros & Farinha da casca de banana \\
\hline Umidade (\%) & $7,74 \pm 0,10$ \\
Acidez total titulável - ATT (\%) & $0,74 \pm 0,03$ \\
pH & $4,72 \pm 0,01$ \\
Atividade de água $\left(\mathrm{a}_{w}\right)$ & $0,44 \pm 0,01$ \\
\hline
\end{tabular}

A baixa umidade é um fator determinante para a estabilidade da farinha, a qual está dentro dos padrões instituídos pela RDC nº 263 (Brasil, 2005), de, no máximo, $15 \%$. Isso se deve ao tempo e à temperatura de desidratação a que as cascas de banana foram submetidas $\left(60^{\circ} \mathrm{C} / 24\right.$ horas). Alcântara et al. (2012) obtiveram $6,04 \%$, ao verificar a umidade da farinha da casca do maracujá, resultado que possibilita maior conservação e tempo de prateleira deste produto.

A farinha obteve valor relativamente baixo para a acidez total titulável, se comparado aos percentuais de Castilho et al. (2014), que obtiveram acidez entre $5,13 \%$ e $5,42 \%$ para a farinha da casca de banana verde do cultivar maçã. Obteve-se um pH de 4,72, o qual corresponde a um dos fatores intrínsecos dos alimentos. O mesmo pode retardar uma possível degradação, através da proliferação de microrganismos, atividades enzimáticas, reações químicas e retenção do sabor e odor.

$\mathrm{Na}$ atividade de água $(0,44)$, foi encontrado um valor de água livre que dificulta a farinha de casca de banana de sofrer a proliferação de microrganismos, elevando sua vida útil. Como se trata de um produto seco, deseja-se que o mesmo não tenha uma atividade de água elevada.

\section{Caracterização físico-química dos doces}

$\mathrm{Na}$ Tabela 3, estão expressos os resultados da caracterização físico-química dos doces, os quais indicaram diferenças significativas a $5 \%$ de probabilidade, em todos os parâmetros, segundo o Teste F. A legislação brasileira, através da Instrução Normativa no 9, da Agência Nacional da Vigilância Sanitária ANVISA, determina os parâmetros de identidade somente para os sólidos solúveis totais (Brasil, 1978).

Os produtos adicionados com farinha da casca de banana obtiveram percentuais menores de umidade em comparação com o valor de $24,97 \%$ da formulação $F_{1}$. Tal fato decorre da substituição da polpa de banana pela farinha, que naturalmente detém uma característica de produto mais seco. Santana et al. (2014), analisando doce de banana, obtiveram valores de umidade $(19,06$ e $35,36 \%)$ com uma ampla variação. As diferenças significativas entre as amostras para umidade podem estar relacionadas não somente à adição de farinha, mas também ao tempo de cocção do doce. Tal fator pode ter durado maior tempo para algumas amostras em relação às outras.

As diferenças estatísticas a $5 \%$ de probabilidade pelo teste de Tukey, obtidas no parâmetro de açúcares redutores entre todas as amostras, permitem inferir que a substituição da polpa por farinha da casca de banana reduziu os valores de açúcares redutores. Resultados inferiores foram encontrados por Silva et al. (2011), ao elaborar doce com polpa de umbu (22,25 a 23,25\%).

Quanto aos açúcares não redutores, verificouse que a adição de farinha influenciou significativamente nos resultados, reduzindo os valores quando adicionada na proporção de $10 \%$. As proporções de açúcares totais dos produtos (39,56 a 77,99\%), por se tratar de doces, contribuem diretamente para melhor conservação e aumento da vida útil, apesar de a substituição da polpa pela farinha ter reduzido os valores encontrados para $\mathrm{F}_{2}$ e $\mathrm{F}_{3}$. 
Tabela 3 - Caracterização físico-química dos doces mariola de banana adicionados de farinha da casca. Physicochemical characterization of banana mariola candies added with banana peel flour.

\begin{tabular}{lrrr}
\hline \multirow{2}{*}{ Parâmetros } & \multicolumn{3}{c}{ Formulações } \\
\cline { 2 - 4 } & \multicolumn{1}{c}{$\mathrm{F}_{1}(0 \%)$} & \multicolumn{1}{c}{$\mathrm{F}_{2}(5 \%)$} & \multicolumn{1}{c}{$\mathrm{F}_{3}(10 \%)$} \\
\hline Umidade (\%) & $24,97 \pm 0,58^{\mathrm{a}}$ & $16,44 \pm 0,64^{\mathrm{c}}$ & $20,99 \pm 1,19^{\mathrm{b}}$ \\
Açúcares redutores (\%) & $51,00 \pm 1,00^{\mathrm{a}}$ & $30,70 \pm 0,82^{\mathrm{b}}$ & $27,52 \pm 0,53^{\mathrm{c}}$ \\
Açúcares não redutores (\%) & $25,64 \pm 1,06^{\mathrm{b}}$ & $31,07 \pm 1,06^{\mathrm{a}}$ & $11,44 \pm 0,72^{\mathrm{b}}$ \\
Açúcares totais (\%) & $77,99 \pm 1,16^{\mathrm{a}}$ & $63,40 \pm 1,49^{\mathrm{b}}$ & $39,56 \pm 0,59^{\mathrm{c}}$ \\
pH & $4,25 \pm 0,07^{\mathrm{c}}$ & $4,63 \pm 0,02^{\mathrm{b}}$ & $4,79 \pm 0,04^{\mathrm{a}}$ \\
Acidez total titulável (ATT - \%) & $0,46 \pm 0,02^{\mathrm{b}}$ & $0,56 \pm 0,04^{\mathrm{a}}$ & $0,59 \pm 0,01^{\mathrm{a}}$ \\
Sólidos solúveis totais (SST - oBrix) & $72,33 \pm 0,58^{\mathrm{c}}$ & $76,66 \pm 0,58^{\mathrm{a}}$ & $74,66 \pm 0,58^{\mathrm{b}}$ \\
Ratio (SST/ATT) & $158,71 \pm 0,87^{\mathrm{a}}$ & $138,44 \pm 1,17^{\mathrm{b}}$ & $126,31 \pm 0,25^{\mathrm{b}}$ \\
Atividade de água (aw) & $0,74 \pm 0,01^{\mathrm{a}}$ & $0,69 \pm 0,01^{\mathrm{b}}$ & $0,65 \pm 0,01^{\mathrm{c}}$ \\
\hline
\end{tabular}

SST - Sólidos Solúveis Totais, ATT - acidez titulável total. Médias seguidas na linha pela mesma letra não diferem estatisticamente entre si, pelo teste de Tukey, a 5\% de probabilidade. SST - Total Soluble Solids, ATT - total titratable acidity. Means followed in the row by the same letter do not differ statistically from each other by the Tukey test at $5 \%$ probability.

A concentração de farinha nas formulações dos doces interferiu no $\mathrm{pH}$, fazendo com que o $\mathrm{pH}$ aumentasse à medida que o percentual de farinha nos doces aumentou. Moura et al. (2014) encontraram valores de $\mathrm{pH}$ inferiores ao desenvolverem doce de goiaba cremoso, relatando leituras entre 3,79 e 4,16. A matéria-prima utilizada (goiaba), que naturalmente é mais ácida, provavelmente, provocou a diminuição do $\mathrm{pH}$ dos doces.

No que diz respeito à acidez, a adição de farinha da casca de banana na formulação dos doces proporcionou leve aumento nos valores de acidez, tornando os doces mais ácidos, mas sem diferença estatística entre as amostras com 5 e 10\% de farinha. Resultados semelhantes foram obtidos por Moura et al. (2014), ao analisarem doces cremosos de goiaba $(0,46-0,56 \%)$.

O doce em massa possui os sólidos solúveis totais (SST) como fator determinante por garantir a consistência e o ponto final de corte do produto. A legislação determina o mínimo de 65 Brix para este parâmetro (Brasil, 1978), estando os doces de banana de acordo com o padrão estabelecido. A adequação foi garantida pelo tempo da cocção do doce durante a elaboração.

$\mathrm{O}{ }^{\circ}$ Brix representa todos os SST presentes na amostra, estando dentro dessa categoria ácidos orgânicos, pigmentos, proteínas, carboidratos (açúcares, pectinas, etc.), minerais, entre outros componentes, sendo o ${ }^{\circ}$ Brix dos doces representado em sua maior parte pelos açúcares. Verifica-se que, com o aumento da concentração de farinha de casca, houve grande redução nos valores de açúcares totais, mas não nos valores de SST, o que pode estar relacionado à presença (principalmente na amostra $F_{3}$ ) de outros constituintes, que não são açúcares, mas que compõem os SST, como proteínas, minerais, etc. Godoy et al. (2009) também perceberam valores de SST dentro do mínimo estabelecido pelas normas vigentes, com variação de aproximadamente 70,00 a $82,66^{\circ}$ Brix em bananadas comerciais.

Quanto maior o valor de atividade de água, maior será a atividade metabólica do alimento e mais facilmente ocorrerão reações hidrolíticas. Assim, a adição de farinha no doce de banana fez com que este ficasse menos propenso ao ataque microbiano e outras reações. O Ratio diminui à medida que foi adicionada farinha da casca de banana, causando a sensação de diminuição de doçura. O Ratio compreende a razão entre $0^{\circ}$ Brix e os ácidos orgânicos.

\section{Avaliação da aceitação sensorial e da intenção e compra dos doces}

A Tabela 4 apresenta os resultados da avaliação sensorial quanto ao teste de aceitação e da intenção de compra dos doces através das notas atribuídas pelos provadores. As formulações elaboradas com farinha $\left(F_{2}\right.$ e $\left.F_{3}\right)$ não diferiram entre si, mas apresentaram diferenças significativas com relação à amostra padrão elaborada sem farinha $\left(F_{1}\right)$. Todos os atributos demonstraram médias acima de 6,00 (gostei ligeiramente), com exceção do atributo sabor, na formulação $\mathrm{F}_{3}$.

Com relação à aparência, o doce $F_{1}$ apresentou melhor aceitação quando comparado aos adicionados da farinha. Verifica-se, então, que a farinha teve interferência negativa na aparência dos doces, uma vez que o doce elaborado somente com a polpa de banana obteve maior índice de aceitabilidade equivalente a $85,33 \%$, enquanto os outros foram decaindo conforme adição de farinha em suas formulações, obtendo $74,0 \%$ e $73,56 \%$ (Figura 1). Godoy et al. (2014), utilizando escala de 1 a 7 , obtiveram resultado de aparência de 5,2 (gostei ligeiramente) para doce de banana tipo corte. 
Tabela 4 - Caracterização sensorial dos doces mariola de banana adicionado de farinha da casca. Sensory characterization of banana mariola candies added with banana peel flour.

\begin{tabular}{lccc}
\hline \multirow{2}{*}{ Atributos } & \multicolumn{3}{c}{ Formulações $^{*}$} \\
\cline { 2 - 4 } & $\mathrm{F}_{1}(0 \%)$ & $\mathrm{F}_{2}(5 \%)$ & $\mathrm{F}_{3}(10 \%)$ \\
\hline Aparência & $7,68^{\mathrm{a}}$ & $6,66^{\mathrm{b}}$ & $6,62^{\mathrm{b}}$ \\
Aroma & $7,22^{\mathrm{a}}$ & $6,58^{\mathrm{b}}$ & $6,22^{\mathrm{b}}$ \\
Consistência & $7,52^{\mathrm{a}}$ & $6,98^{\mathrm{b}}$ & $6,64^{\mathrm{b}}$ \\
Cor & $7,74^{\mathrm{a}}$ & $6,42^{\mathrm{b}}$ & $6,36^{\mathrm{b}}$ \\
Sabor & $7,80^{\mathrm{a}}$ & $6,68^{\mathrm{b}}$ & $5,82^{\mathrm{b}}$ \\
Doçura & $7,78^{\mathrm{a}}$ & $6,92^{\mathrm{b}}$ & $6,38^{\mathrm{b}}$ \\
Impressão global & $7,84^{\mathrm{a}}$ & $7,00^{\mathrm{b}}$ & $6,44^{\mathrm{b}}$ \\
Intenção de compra & $4,34^{\mathrm{a}}$ & $3,74^{\mathrm{b}}$ & $3,20^{\mathrm{b}}$ \\
\hline
\end{tabular}

${ }^{*}$ Médias seguidas na linha pela mesma letra não diferem estatisticamente entre si, pelo teste de Tukey, a $5 \%$ de probabilidade. Means followed in the row by the same letter do not differ statistically from each other by the Tukey test at $5 \%$ probability.

Em relação ao aroma, o doce $F_{1}$ obteve nota superior em relação a $F_{2}$ e $F_{3}$. Ou seja, a adição da farinha fez com que os produtos perdessem o aroma característico do doce de banana, promovendo redução das notas atribuídas a esse parâmetro, refletindo em seu índice de aceitabilidade (Figura 1). Esse índice resultou em valores decrescentes com a adição da farinha: $80,22 \%$ ( $0 \%$ de farinha), $73,11 \%$ (5\% de farinha) e $69,11 \%$ (10\% de farinha). Godoy et al. (2014) obtiveram notas 5,1 (gostei ligeiramente), mas na escala de 7 pontos em doce de banana tipo corte.

A consistência do doce foi alterada com a adição da farinha em sua composição, ficando mais pegajosa e dificultando o corte. Isso levou os índices de aceitabilidade (Figura 1) nesse parâmetro a serem menores, resultando em 83,56\% $\left(F_{1}\right), 77,56 \%\left(F_{2}\right)$ e $73,78 \%\left(F_{3}\right)$.

No atributo de cor, as formulações $F_{2}$ e $F_{3}$ apresentaram notas similares, estaticamente entre si, e inferiores a $F_{1}$. Isso se deve à adição da farinha que apresentava coloração escura, transferindo essa característica aos doces. Devido a isto, os doces com farinha apresentaram cor mais escura e diferente do doce de banana tradicional (mais claro); por esse motivo, $F_{1}$ (sem farinha) obteve o maior índice de aceitabilidade $(86,00 \%)$ para o atributo cor. Carneiro et al. (2009) obtiveram resultados semelhantes ao investigar a cor de doces de goiaba, obtendo notas de 6,25 a 7,25 .

Quanto a sabor, os doces obtiveram notas entre 5,82 e 7,80. Verifica-se, assim, que quanto maior a adição de farinha ao doce, menos aceitável foi o sabor pelos provadores, uma vez que a farinha da casca apresenta um sabor característico que irá sobressair-se em relação ao sabor da polpa de banana, distanciando-se do sabor comumente encontrado para o doce de banana. Esse fator negativo fez com que sua aceitação diminuísse à medida que se adicionava mais farinha em sua composição e reduzisse seu índice de aceitabilidade (Figura 1). O doce $\mathrm{F}_{3}$ obteve menor índice de aceitação 64,67\%, enquanto que $F_{1}$ e $F_{2}$ foram superiores. Campos et al.
(2015), ao desenvolver um doce em massa de maracujá e goiaba, encontraram resultados semelhantes de 7,58 a 7,86 .

Para a doçura, verifica-se o mesmo comportamento apresentado para o sabor, em que as notas obtidas foram diminuindo com a adição de farinha de $7,78\left(F_{1}-0 \%\right)$ para $6,38\left(F_{3}-10 \%\right)$, indicando portanto, que a adição da farinha diminuiu a sensação de doçura do produto, correlacionando-se com a redução dos valores de açúcares (totais, redutores e não redutores) e Ratio (Tabela 3 ) nos doces. A amostra elaborada sem a adição de farinha $\left(F_{1}\right)$, foi a que apresentou o maior índice de aceitação, tanto para o sabor como para doçura, assim como os maiores valores de açúcares redutores, açúcares totais e Ratio (Tabela 3).

Verificou-se que o doce obteve impressão global melhor para $F_{1}(7,84)$, diferindo significativamente de $F_{2}(7,00)$ e $F_{3}(6,44)$, que não diferiram entre si e apresentaram resultados inferiores, provavelmente pela interferência da substituição da polpa de banana pela farinha de casca de banana. Campos et al. (2015) obtiveram índices próximos $(7,72$ a 7,90$)$ ao elaborar um doce em massa de maracujá com goiaba.

Quanto à intenção de compra (Tabela 4), constataram-se notas entre 3 (talvez comprasse/talvez não comprasse) e 4 (possivelmente compraria o produto). A concentração de farinha causou maior rejeição com o aumento de sua concentração na composição dos doces $F_{2}$ e $F_{3}$.

A Figura 2 apresenta o índice de aceitabilidade geral dos provadores em relação aos doces tipo mariola de banana adicionados de farinha da casca. Segundo Dutcosky (2013), o índice de aceitabilidade de $70 \%$ é o valor mínimo para que um produto seja considerado aceito, em termos de suas propriedades sensoriais para ser lançado no mercado. Deste modo, todas as formulações apresentaram índices de aceitabilidade superiores a $70 \%$ e estatisticamente diferentes, demonstrando que os produtos obtiveram boa aceitação e que a adição da farinha pode ser viável, porém em baixas concentrações. 

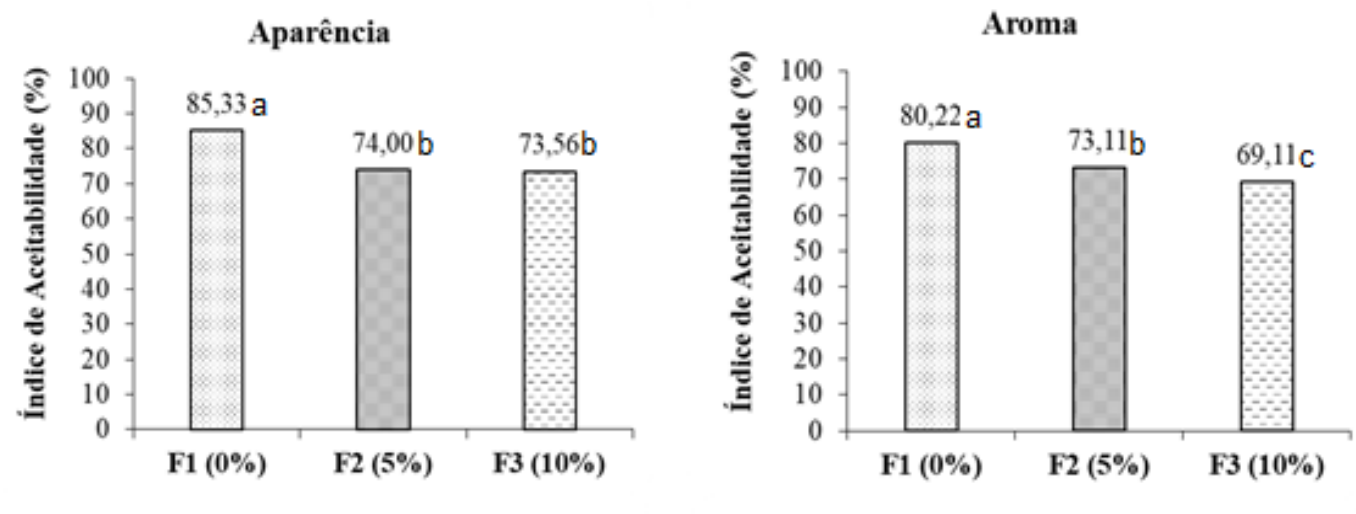

Consistência
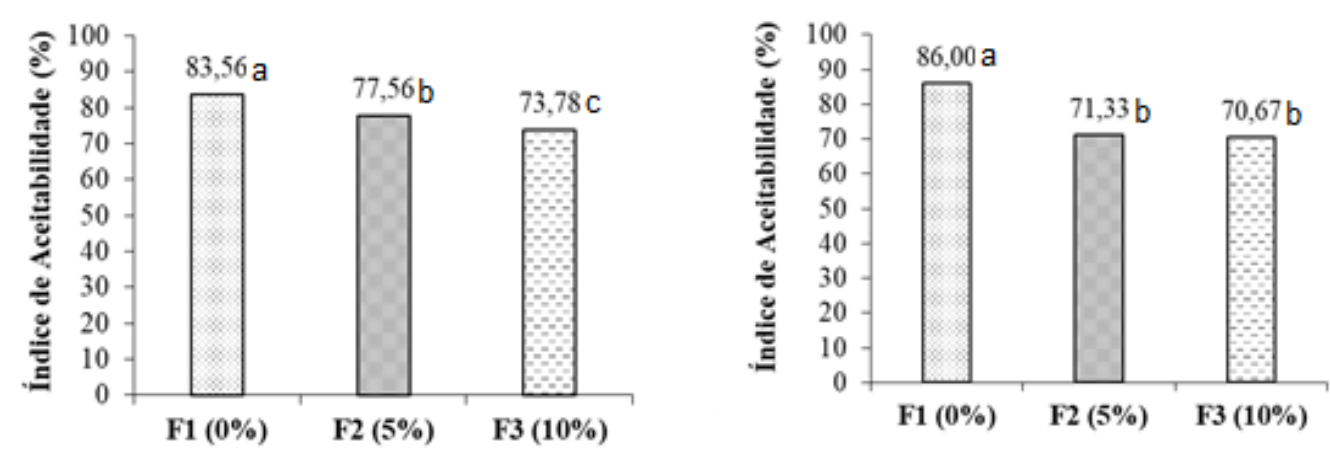

Doçura
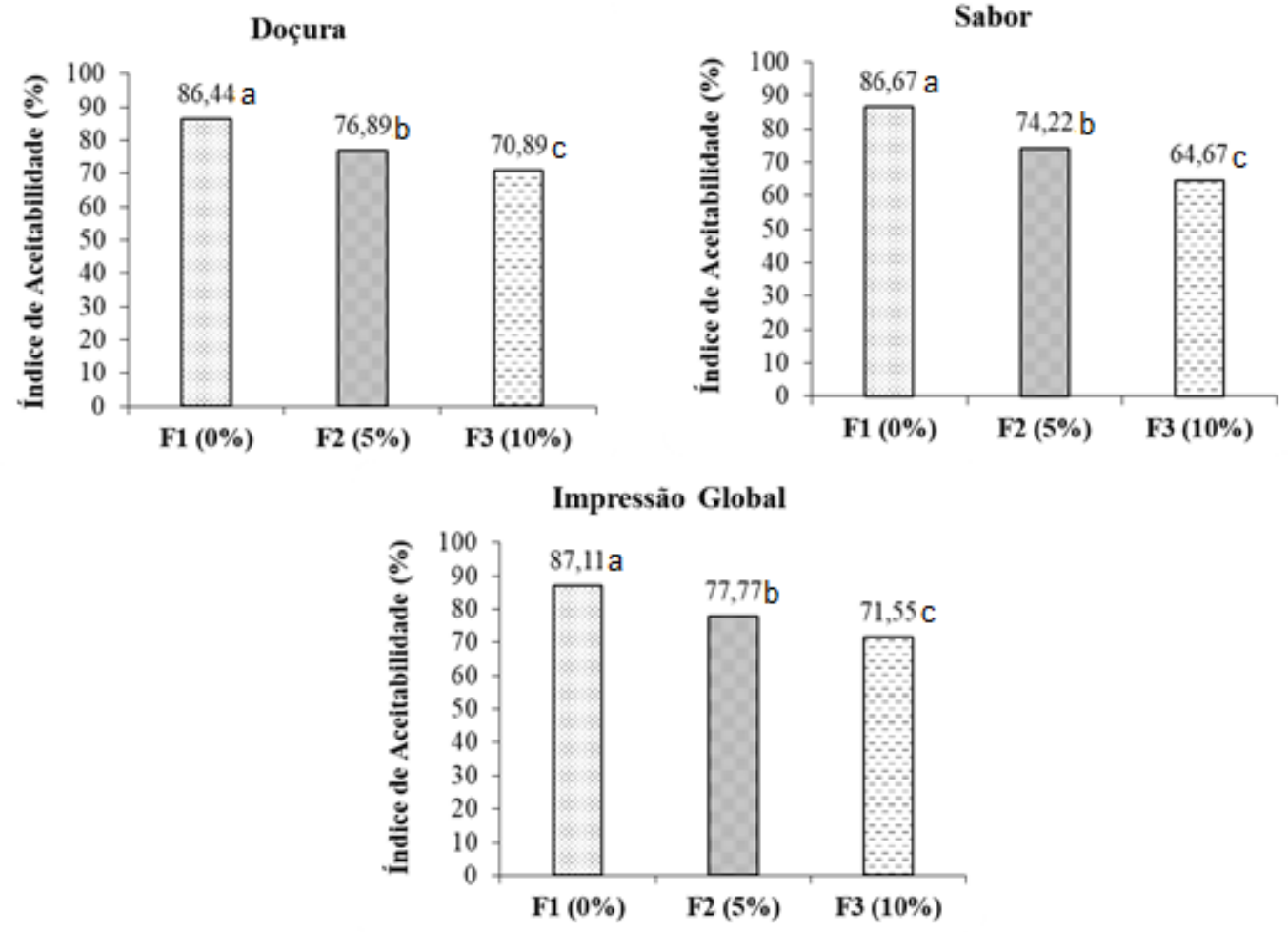

Figura 1 - Índice de aceitabilidade dos atributos sensoriais dos doces tipo mariola de banana. Acceptability index of the sensory attributes of banana candies mariola type. 


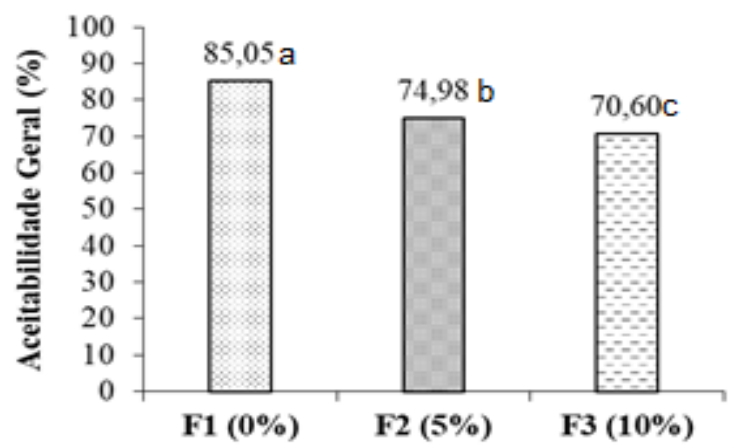

Figura 2 - Índice de aceitabilidade geral dos doces tipo mariola de banana. Acceptability index general of the sensory attributes of banana candies mariola type.

\section{Conclusões}

Os doces atenderam ao parâmetro legislativo de sólidos solúveis totais, porém a substituição da polpa pela farinha interferiu, reduzindo os parâmetros de açúcares totais, Ratio e atividade de água.

Os doces de banana, com a substituição da polpa de banana pela farinha da casca de banana, possuem perspectivas positivas; no entanto, o doce elaborado sem adição da farinha foi mais bem aceito sensorialmente. A adição de farinha nos doces de banana tipo mariola é uma alternativa viável para o reaproveitamento dos resíduos da fruta, embora os doces devam ser elaborados com concentrações inferiores a $10 \%$ de farinha da casca, visando a melhor apreço sensorial.

\section{Referências}

Alcântara SR, Sousa ABC, Almeida FAC, Gomes JP (2012) Caracterização físico-química das farinhas do pedúnculo do caju e da casca do maracujá. Revista Brasileira de Produtos Agroindustriais 14 (Especial): 473-478.

Brasil. Agencia Nacional de Vigilância Sanitária ANVISA (1978). Resolução Normativa no 9, de 1978 da Câmara Técnica de Alimentos. Diário Oficial [da] República Federativa do Brasil, Brasília, 04 mai. 1978.

Brasil. Agencia nacional de vigilância sanitária ANVISA (2005). Resolução Normativa n. 263/2005 da Câmara Técnica de Alimentos. Diário Oficial [da] República Federativa do Brasil, Brasília, 04 set. 2005.

Campos KF, Melo ABP, Fontes CPML (2015) Desenvolvimento de doce em massa de maracujá e goiaba enriquecido com farinha de maracujá. Revista Brasileira de Agrotecnologia 1 (5): 99-102.

Carneiro LC, Bezerra AMM, Guedes JAM (2009) Fabricação de doce de goiaba com aproveitamento do albedo do maracujá amarelo. Revista Holos 4 (1): 26-32.
Castilho LG, Alcantara BM, Clemente E (2014) Desenvolvimento e análise físico-química da farinha da casca, da casca in natura e da polpa de banana verde das cultivares maçã e prata. Revista E-xacta 7 (2): 07-114.

Dutcosky SD (2013) Análise sensorial de alimentos. Editora Universitária Champagnat 4: 531p.

Ebrahimi MA, Mohtasebi SS, Rafiee SH, Hosseinpour S (2012) Investigation of banana slices shrinkage using image processing technique. Australian Journal of Crop Science 6(5): 938-945.

Godoy RCB, Matos ELS, Santos DV, Amorim TS, Waszczynskyj N, Sousa M A (2009) Estudo da composição físico-química e aceitação de bananadas comerciais por meio de análise multivariada. Revista do Instituto Adolfo Lutz 68(3): 375-380.

Godoy RCB, Waszczynskj N, Santos, GG, Santana FA, Ledo CAS, Silva SO, Garruti DS (2014) Avaliação sensorial de doces de banana de corte elaborados com genótipos resistentes à sigatoka-negra. Revista Brasileira de Produtos Agroindustriais 16 (2): 127-136.

IAL Instituto Adolfo Lutz (2008) Métodos físico-químicos para análise de alimentos. Digital 4: 1020p.

Li L, Hanniken M, Yuan Y, Hao G, Ge X (2010) Molecular phylogeny and systematics of the banana family (Musaceae) inferred from multiple nuclear and chloroplast DNA fragments, with special reference to the genus Musa. Molecular Phylogenetics and Evolution 57(1): $1-10$.

Moura RL, Silva AP, Lima SP, Souza PA (2014) Avaliação da qualidade físico-química em doces cremosos de goiaba comercializados em Limoeiro do Norte-CE. Revista Verde de Agroecologia e Desenvolvimento Sustentável 9 (3): 303 - 306.

Rufino MSN, Alves RE, Brito ES, Pérez-Jimnénes J, Saura-Calixto F, Mancini-Filho J (2010) Bioactive compounds and antioxidant capacities of 18 non-traditional tropical fruits from Brazil. Food Chemistry, Barking 121: $996-1002$. 
Santana DCN, Alvez AMA, Santos AF, Bezerra JM, Araújo JFS (2014) Qualidade de doce em massa de banana adicionado de componentes funcionais. Caderno Verde de Agroecologia e Desenvolvimento Sustentável 4 (1): 2358-2367.

Silva JP, Netto-Oliveira ER, Pereira SCM, Monteiro ARG (2014) Avaliação físico-química e sensorial de pães produzidos com substituição parcial de farinha de trigo por farinha de banana verde. Revista Brasileira de Pesquisa em Alimentos 5(3):1-7.
Silva MSS, Figueiredo RMF, Queiroz AJM, Santiago VMS (2011) Avaliação físico-química e sensorial de doces cremosos produzidos com soro de leite de cabra, leite de vaca e polpa de umbu. Revista Brasileira de Produtos Agroindustriais, 13 (Especial): 397-410.

Storck RC, Nunes LG, Oliveira BB, Basso C (2013) Folhas, talos, cascas e sementes de vegetais: composição nutricional, aproveitamento na alimentação e análise sensorial de preparações. Revista Ciência Rural 43 (3): 537-543. 